\title{
Control of welding distortion during gas metal arc welding of AH36 plates by stress engineering
}

\author{
A. M. A. Pazooki ${ }^{1}$ • M. J. M. Hermans ${ }^{2}$ - I. M. Richardson ${ }^{2}$
}

Received: 13 February 2016 / Accepted: 2 May 2016 / Published online: 14 May 2016

(C) The Author(s) 2016. This article is published with open access at Springerlink.com

\begin{abstract}
Welding residual stress and distortion are strongly linked together. One of the ways to control or reduce the welding distortions is the manipulation of the generated stresses during welding, and final residual stresses exist in the workpiece (stress engineering). In this paper, the control of gas metal arc butt welding distortion of $500 \times 250 \times 6 \mathrm{~mm}^{3} \mathrm{AH} 36$ plates by means of additional heat sources is studied using experimental and numerical approaches. To understand the distortion reduction mechanism, 3D finite element model has been constructed and validated by temperature, distortion and residual stress measurements together with microstructure investigation. The numerical results are compared to that of the experimental measurements.
\end{abstract}

Keywords Welding with additional heating $\cdot$ Side heating · Residual stress $\cdot$ Welding distortion $\cdot$ FEM $\cdot$ AH36

\section{Background}

Welding distortion is a permanent change in shape of a component (or an instability) due to the welding-induced

A. M. A. Pazooki

masoud.pazooki@gmail.com

1 Material innovation institute (M2i), Elektronicaweg 25, 2628 XG Delft, The Netherlands

2 Department of Material Science and Engineering, Delft University of Technology, Mekelweg 2, 2628CD Delft, The Netherlands stresses [1,2]. Six types of welding distortion are defined $[2,3]$ :

- Transverse shrinkage (shrinkage perpendicular to the weld)

- Longitudinal shrinkage (shrinkage in the direction of the weld)

- Rotational distortion (angular distortion in the plane of the plate due to thermal expansion or contraction)

- Angular distortion (shrinkage caused by a non-uniform temperature distribution in the through-thickness direction of the workpiece)

- Bending distortion (distortion in a plane through the weld line and perpendicular to the plate)

- Buckling (distortion caused by compressive stresses)

Figure 1 shows the different types of welding distortion [4]. It should be mentioned that in reality, multiple types of welding distortion may occur at the same time and that it is sometimes difficult to distinguish the types of distortion present in a workpiece [4].

As reported in [5], in 1990, a Japanese Patent showed a method to reduce buckling deformation for thin metal sheet using additional heating sources parallel to the welding torch located at or near plates' edges. The method is applicable for the materials with thickness higher than $4 \mathrm{~mm}$. Since the heaters are located rather far to the welding torch, the method is called side heating. In this paper, attempts have been made to study the welding with additional heating of AH36 plates with dimensions of $500 \times 250 \times 6 \mathrm{~mm}^{3}$. Both experimental and numerical approaches have been used in this investigation. The results of such approaches are compared for two situations: (1) conventional welding and (2) welding with additional heating. 
Fig. 1 Different types of welding distortions [4]
Table 1 The chemical composition of AH36 steel [6], Fe balance
Table 2 Chemical composition for ER70S-3 filler wire [7], Fe balance
Transverse shrinkage

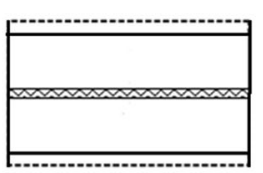

Longitudinal shrinkage
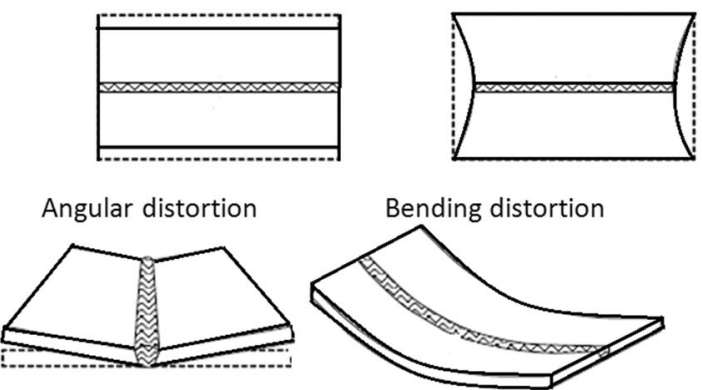

Rotational distortion
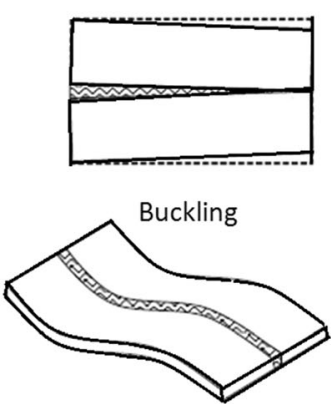

\begin{tabular}{lllllllllll}
\hline & $\mathrm{C}$ & $\mathrm{Mn}$ & $\mathrm{Si}$ & $\mathrm{Cr}$ & $\mathrm{Ni}$ & $\mathrm{Al}$ & $\mathrm{Cu}$ & $\mathrm{V}$ & $\mathrm{Ti}$ & $\mathrm{Nb}$ \\
\hline Max wt\% & 0.124 & 1.42 & 0.465 & 0.026 & 0.017 & 0.040 & 0.018 & 0.003 & 0.003 & 0.020 \\
\hline
\end{tabular}

\begin{tabular}{lllllllllll}
\hline & $\mathrm{C}$ & $\mathrm{Mn}$ & $\mathrm{Si}$ & $\mathrm{Cu}$ & $\mathrm{P}$ & $\mathrm{S}$ & $\mathrm{Cr}$ & $\mathrm{V}$ & $\mathrm{Mo}$ & $\mathrm{Ni}$ \\
\hline Max wt\% & $0.06-0.15$ & $0.9-1.4$ & $0.45-0.75$ & 0.5 & 0.025 & 0.035 & total $<0.5$ & \\
\hline
\end{tabular}

\section{Material}

AH36 steel is a grade of ASTM A131 steel. This is a moderate strength hot rolled steel, mainly used in shipbuilding [6]. The steel has a ferritic-pearlitic microstructure. The material undergoes solid state phase transformations during welding. Table 1 shows the chemical composition of such steel.

\section{Conventional welding and welding with additional heating}

AH36 plates with dimension of $500 \times 250 \times 6 \mathrm{~mm}^{3}$ were welded by means of gas metal arc welding (GMAW). The welding power source was a Cloos-Quinto Profi 503. The welding torch was tilted to an angle of around $60^{\circ}$ to the plane of the plate (leading the weld pool). A Lincoln electric LNM 25TM filler wire with a diameter of $1.2 \mathrm{~mm}$ was used. According to AWS A5.18 specification [7], the electrode is classified as ER70S-3 with a chemical composition given in Table 2 .

In order to achieve a fully penetrated weld, a Y-groove joint was employed with dimensions shown in Fig. 2.

The shielding gas used for GMA welding was $85 \% \mathrm{Ar}$ $15 \% \mathrm{CO}_{2}$. This mixture of shielding gasses provides a stable arc, low spatter losses and acceptable weld bead profile. The shielding gas flow rate was $151 \mathrm{~min}^{-1}$.

The clamping system consists of a steel backing frame with dimensions of $735 \times 1200 \times 30 \mathrm{~mm}^{3}$. A $30 \mathrm{~mm}$ deep and $20 \mathrm{~mm}$ wide groove is located at the centre of the backing plate in order to apply the backing gas (and the ceramic backing) as shown in Fig. 3. Four steel strips with dimensions of $660 \times 32 \times 10 \mathrm{~mm}^{3}$ were used to evenly distribute the clamping pressure to the workpiece. The average welding current and voltage were $200.2 \mathrm{~A}$ and $25.9 \mathrm{~V}$, respectively. The speed of welding was set to $4.5 \mathrm{~mm} \mathrm{~s}^{-1}$, while the wire feed rate was $5.7 \mathrm{~mm} \mathrm{~s}^{-1}$.

In addition to the groove at the centre of the backing plate, a similar groove was made at $250 \mathrm{~mm}$ from the starting point of welding, perpendicular to the welding direction, to allow temperature measurements by means of thermocouples at the underside surface of the workpiece.

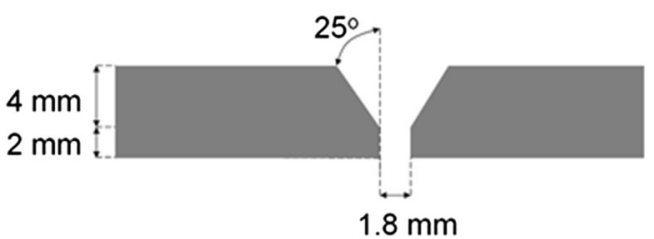

Fig. 2 The Y-groove joint design used during welding of $6 \mathrm{~mm}$ thick AH36 steel 
Fig. 3 Schematic drawing of the positions of the clamps for large plates

Fig. 4 A schematic drawing of the positional process parameters involved in welding with additional heat sources: Burner separation (BB), Burner distance to the welding torch (BT) and Burner distance to the plate (BP)
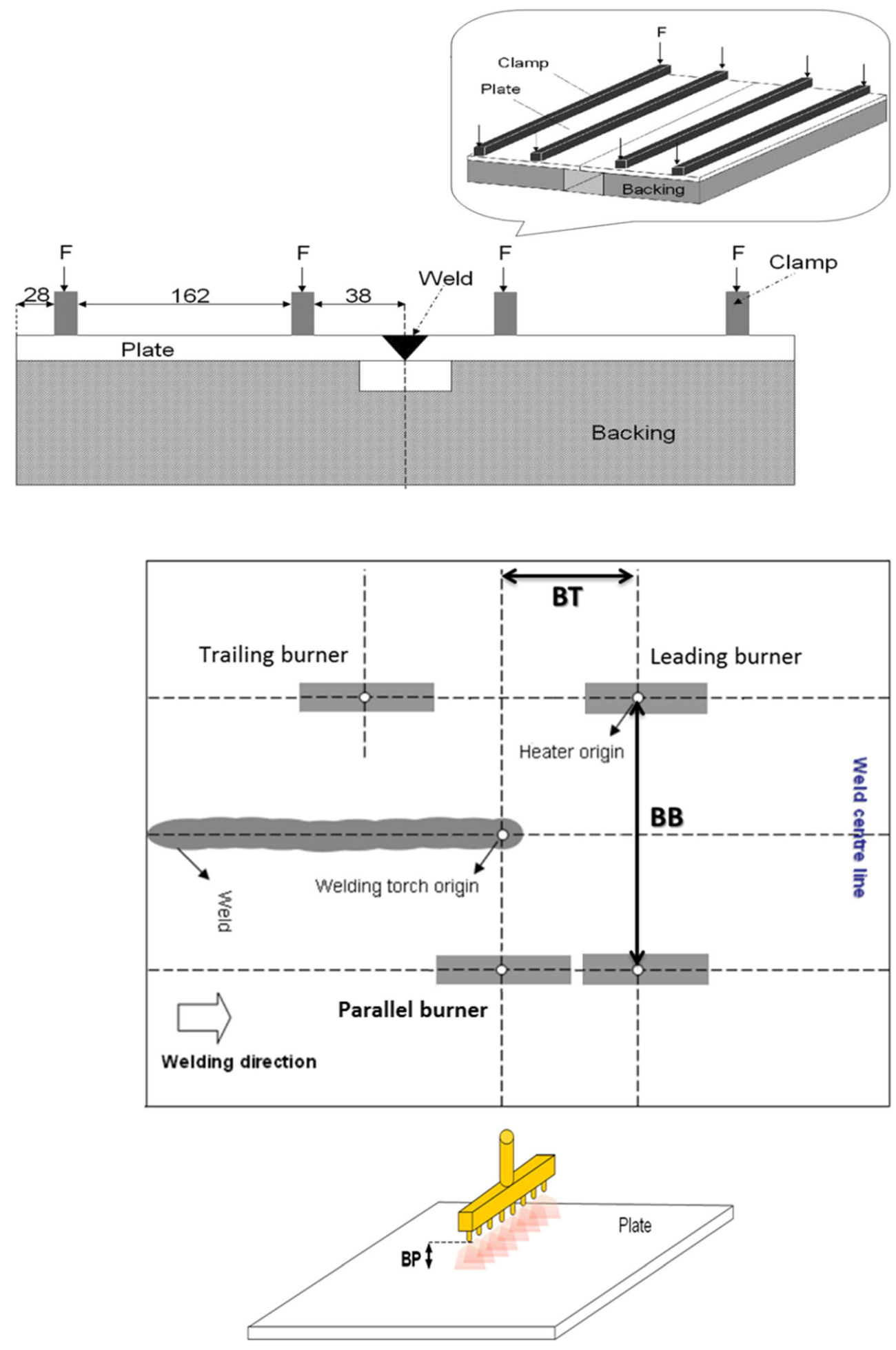

\begin{tabular}{ll} 
Case/set & Value \\
\hline Separation of burners $(\mathrm{mm})$ & 227 to 427 \\
Welding torch to burners distance $(\mathrm{mm})$ & -220 to 220 \\
Maximum temperature at the underside surface of the plate $\left({ }^{\circ} \mathrm{C}\right)$ & Up to 400
\end{tabular}

Table 3 The range of process parameters used in the experiments for different materials 


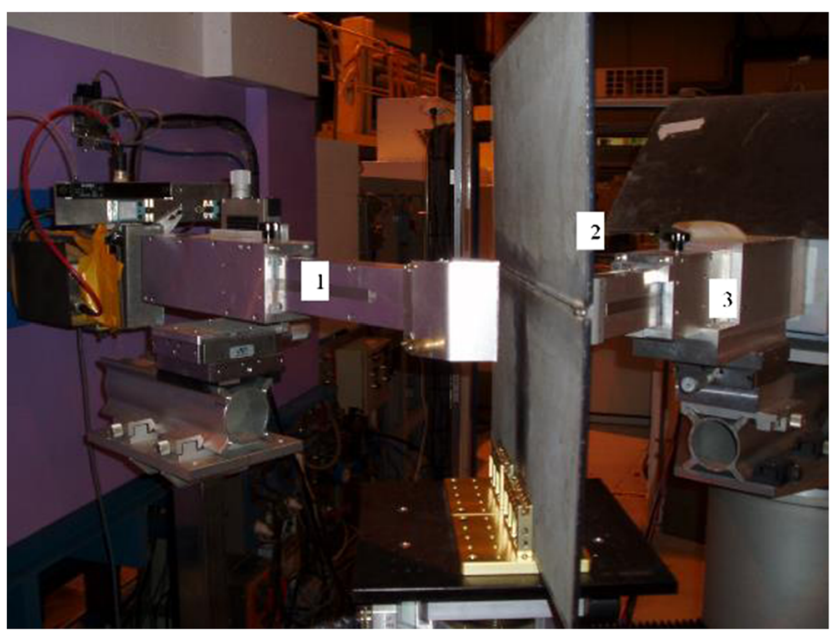

Fig. 5 Overview of the set-up for the neutron diffraction measurements at LBB. The numbers indicate neutron guide (1), the sample (2) and the collimator (3)

In welding with additional heating, the burners can be installed either parallel or perpendicular to the weld centre line. It was practically impossible to test the burner assembly perpendicular to the weld centre line due to geometric limitations. Therefore, in all experiments, the burners were installed parallel to the weld centre line as shown in Fig. 4.

The new set-up was based on the rectangular LINDOFLAMM® (http://www.lindegas.com/) special short lance burners. The burner operates according to DIN EN ISO 5172 [8] with compressed air and acetylene. Basically, it consists of a burner head, a mixing pipe, a mixing chamber with a pressure regulator and a handle. The total length of the burner is $240 \mathrm{~mm}$ and includes eight nozzles with $30-\mathrm{mm}$ separation distance. The width of the burner is $27 \mathrm{~mm}$. The
Table 4 Parameter values used in the simulation

\begin{tabular}{ll}
\hline Parameter & Value \\
\hline Welding source half width (mm) & 5 \\
Welding source depth (mm) & 6 \\
Welding source forward length & 10 \\
Welding source backward length & 5 \\
Efficiency of the welding process & $75 \%$ \\
Welding power (W) & 5185.18 \\
Max heat flux in additional heating $\left(\mathrm{kW} \mathrm{m}^{-2}\right)$ & 375.4 \\
\hline
\end{tabular}

working pressure at the burner inlet is 0.5 bar for acetylene and 1.5-4.0 bar for compressed air. This gives a consumption of $0.3-3.2 \mathrm{~m}^{3} \mathrm{~h}^{-1}$ for acetylene and $2.1-22.4 \mathrm{~m}^{3} \mathrm{~h}^{-1}$ for compressed air. The burners were adjusted by turning the acetylene and oxygen valves on the regulator to control the gas flow and to obtain the required flame for welding with additional heating.

The first step in the experiments is the setting of the burners for different peak temperatures. The maximum temperatures for different burner settings were measured at the underside surface of the plate by means of thermocouples. A series of trials was performed for a number of pressurised air-acetylene flame settings, i.e., different peak temperatures. In this way, the mixtures were calibrated for different peak temperatures. These tests were repeated for the different base materials. Table 3 shows the range of the maximum temperatures obtained and position parameters.

The distance of the burners to the plate (BP) was set to $40 \mathrm{~mm}$ for AH36 sheets in order to increase the heat input.
Fig. 6 The models used in the simulations with $500 \$$ times $\$ 500 \$ \backslash$ times $\$ 6$ $\mathrm{mm} \$ \wedge 3 \$$ (the cross section is shown on the left side
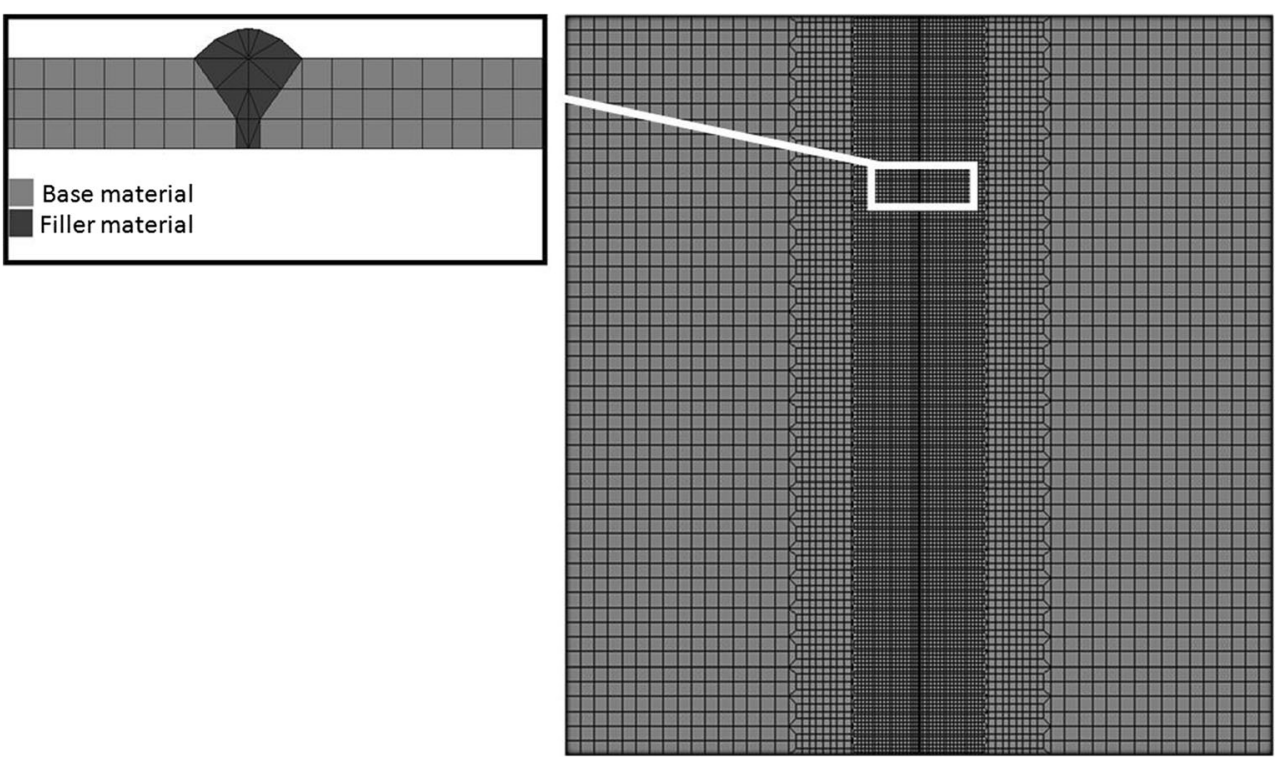
Fig. 7 The effect of the welding with additional heating temperature on the distortion index for AH36 plate

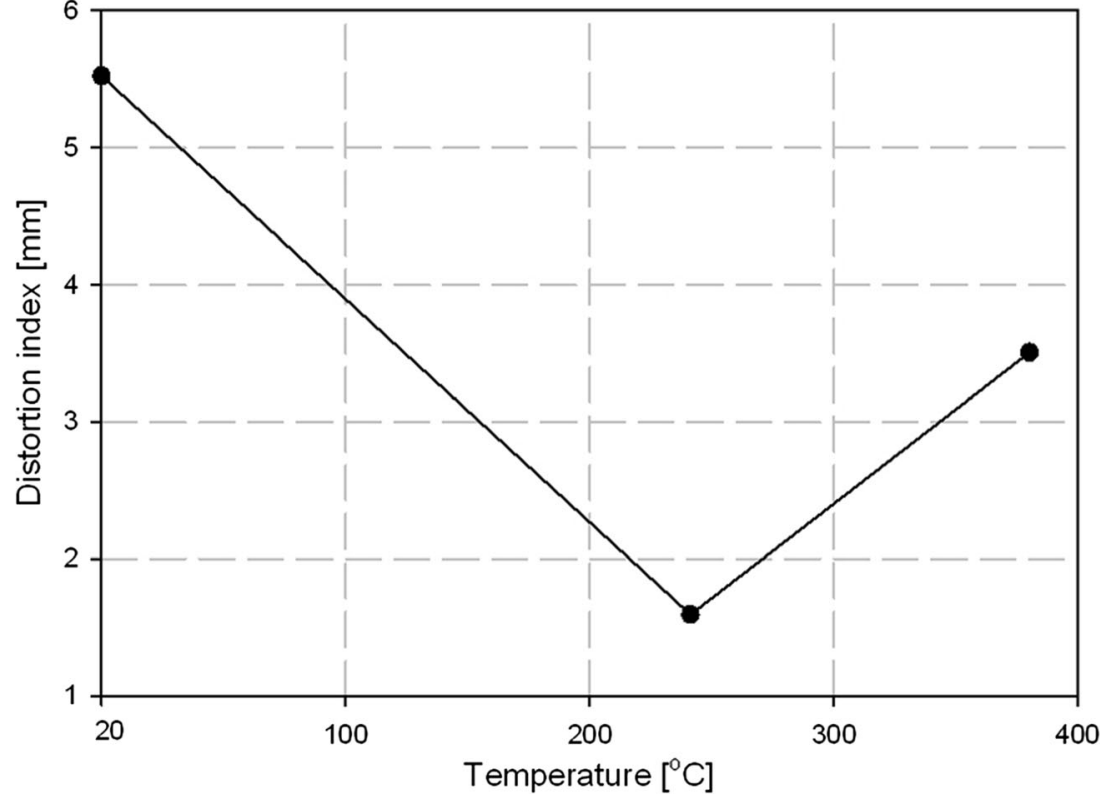

\section{Experiments}

The out-of-plane distortions of the plates before and after welding and welding with additional heating were measured by means of the digital image correlation method with an accuracy of $50 \mu \mathrm{m}$. In order to make the comparison of the experiments simple and fast, a distortion index is defined based on the result of DIC measurements. The distortion index is the difference between the maximum and the minimum outof-plane deformation of a plate.
The temperature of the workpiece during both conventional welding and welding with additional heating was measured by means of k-type thermocouples with diameter of $0.25 \mathrm{~mm}$. The thermocouples were installed along or perpendicular to the heating (or welding) line. The exact position of thermocouples was measured after welding. The burner-induced temperature is defined as the temperature at the underside surface of the plate beneath the burner.

The microstructure of the weld metal, the heat-affected zone of the weld (HAZ-welding), the base metal and the
Fig. 8 The effect of the burner separation distance on the distortion index for AH36 plate after conventional welding and welding with additional trailing heating

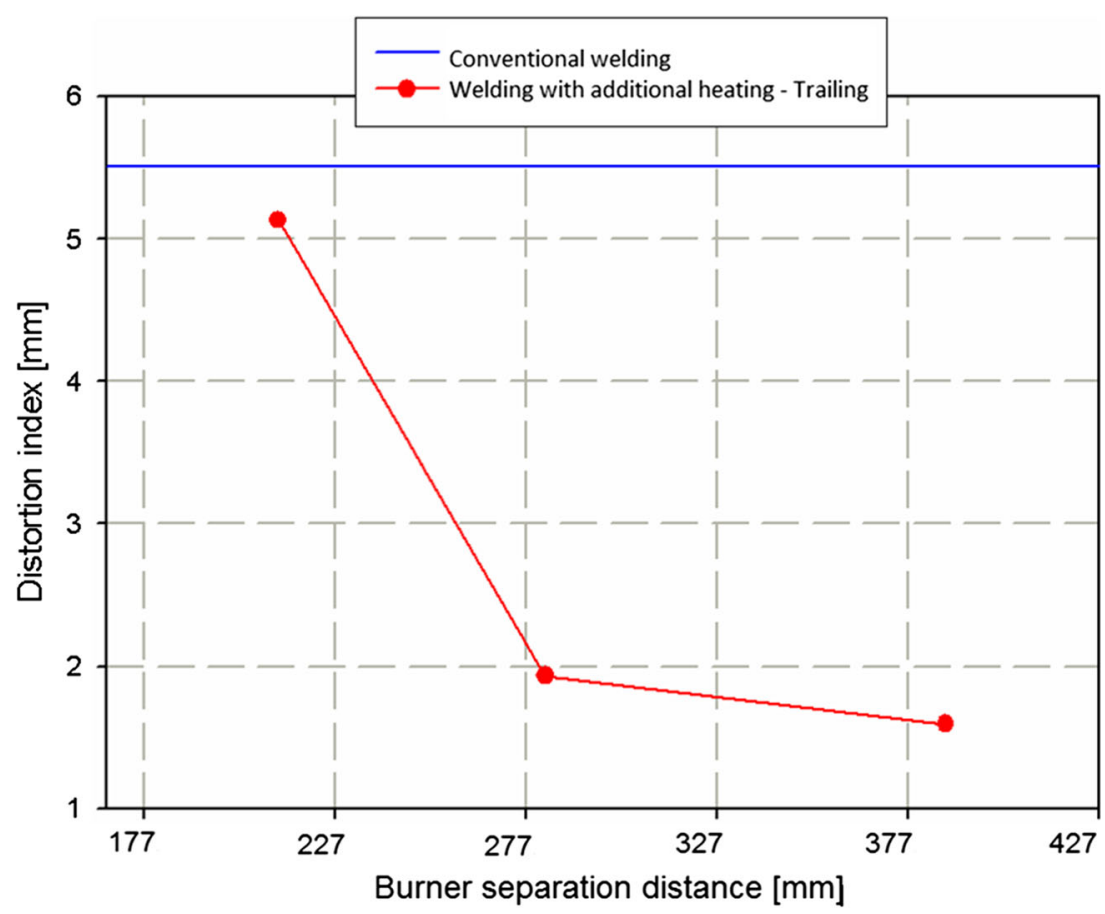


Fig. 9 The effect of the burner distance to the welding torch on the distortion index of AH36 plate after welding with additional heating. The burner separation is $387 \mathrm{~mm}$

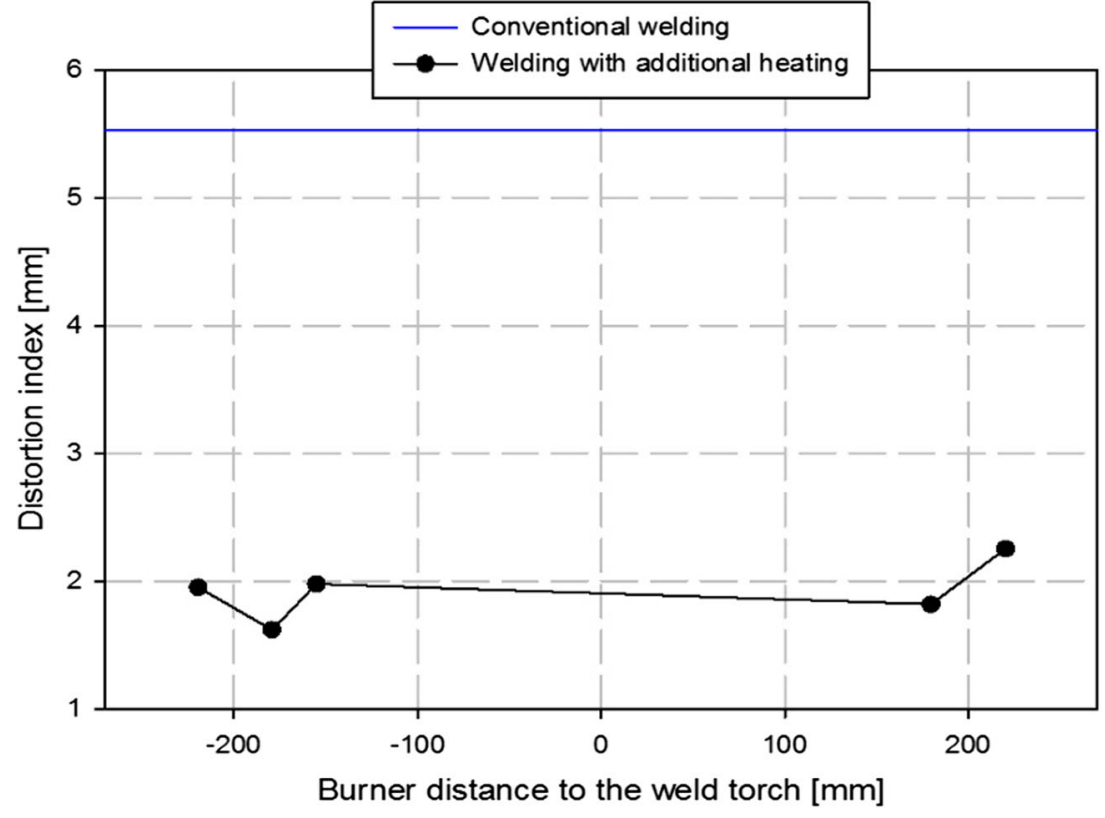

heated area beneath the burners (HAZ-welding with additional heating) were studied at a cross section perpendicular to the weld and in the middle of the plate using a $5 \%$ Nital etching solution for $10 \mathrm{~s}$. Hardness profiles were also taken across the welds, the heat-affected zones and the heated areas beneath the additional heating burners, for different materials using Vickers micro-hardness measurements with an indentation load of $300 \mathrm{~g}$.

Residual stress measurements were performed by means of the neutron diffraction (ND) method at the Laboratoire Leon Brillouin (LLB) France. The samples were welded conventionally and welding with additional heating and full penetration was obtained. Figure 5 shows a picture of the arrangement. The diffraction measurements were performed on the $\mathrm{Fe}(211)$. This plane is known to be the least sensitive to the inter-granular stress effects. The residual stress profile of samples in the clamped condition was measured using a portable X-ray equipment.

\section{Numerical approach}

The numerical approach is based on 3D decoupled thermomechanical finite element model for both conventional welding and welding with additional heating using Msc.Marc as the commercial code.

The thermal model includes the modelling of the welding heat by the volumetric heat flux with Gaussian distribution proposed by Goldak [9] input and the modelling of heat losses by convection, radiation and conduction. The burners in welding with side heating are modelled by eight circular Gaussian heat flux distributions with an inter-distance of $30 \mathrm{~mm}$. The suitable power
Fig. 10 The final out-of-plane deformation of AH36 plate after a conventional welding and $\mathbf{b}$ welding with additional heating with experimentally obtained minimum distortion
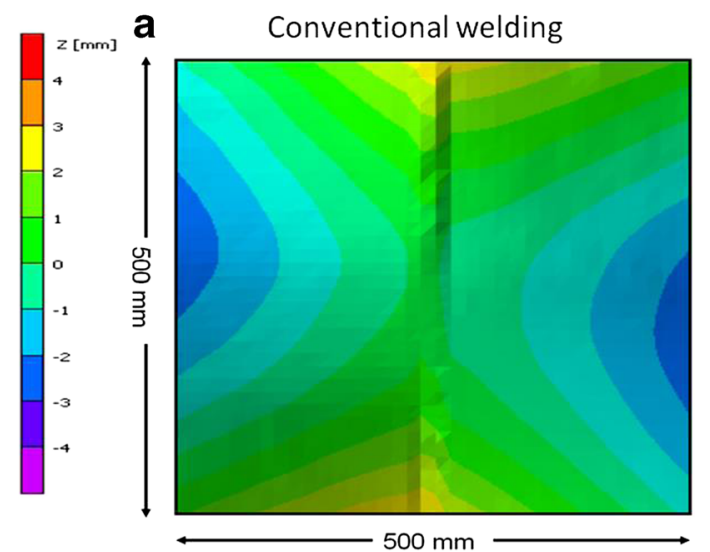

b Welding with additional heating

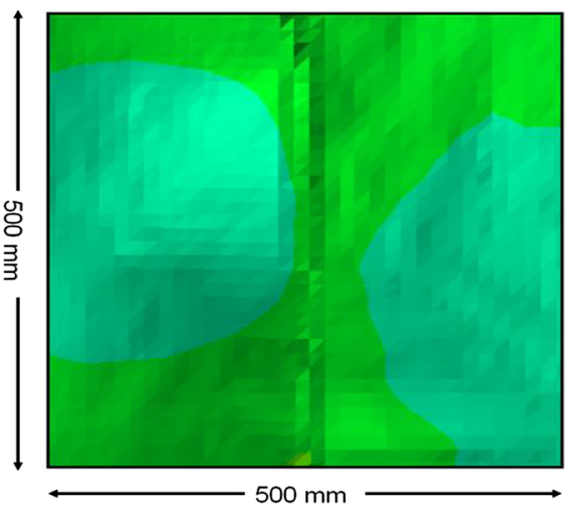


Fig. 11 Temperature as a function of time for conventional welding of AH36 plates at several positions from the weld centre line

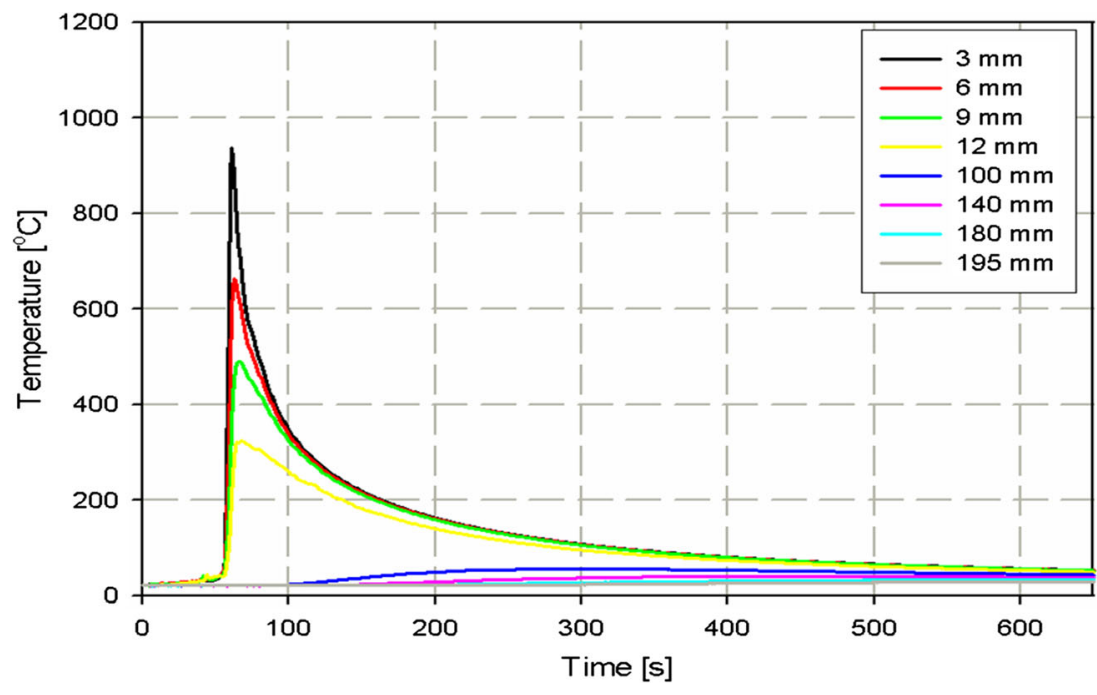

density distribution is obtained by comparing the temperature predictions and measurements. The mesh used in the simulations is shown in Fig. 6. The parameters for thermal modelling are summarised in Table 4 . The thermal material properties were obtained from [10] and [11].

The mechanical models for both conventional welding and welding with additional heating consist of the modelling of clamps using spring links and plastic strain resetting at melting temperature. Isotropic hardening model was used in the models. The mechanical material properties are obtained using data from [12].

The filler wire is modelled using the deactivated element method. This means that filler elements are initially available in the model with scaled down material properties. The filler elements are only thermally activated initially and remain inactive on the mechanical side. If the thermal activation time is zero, the filler elements are activated on the mechanical side in the next increment. If the thermal activation time is non-zero, the filler elements remain mechanically inactive until the thermal activation time is passed [13].

\section{Experimental results and discussion}

The temperature effect of additional heating on the distortion index for AH36 plate is shown in Fig. 7. The conventional welding has a distortion index of $5.5 \mathrm{~mm}$. By increasing the burner-induced temperature, the distortion index is decreased first and then it starts to increase. The suitable temperature was found to be around $240{ }^{\circ} \mathrm{C}$. This temperature is used for the other additional heating
Fig. 12 Temperature measurements for welding with additional heating of AH36 plates at different positions from the weld centre line

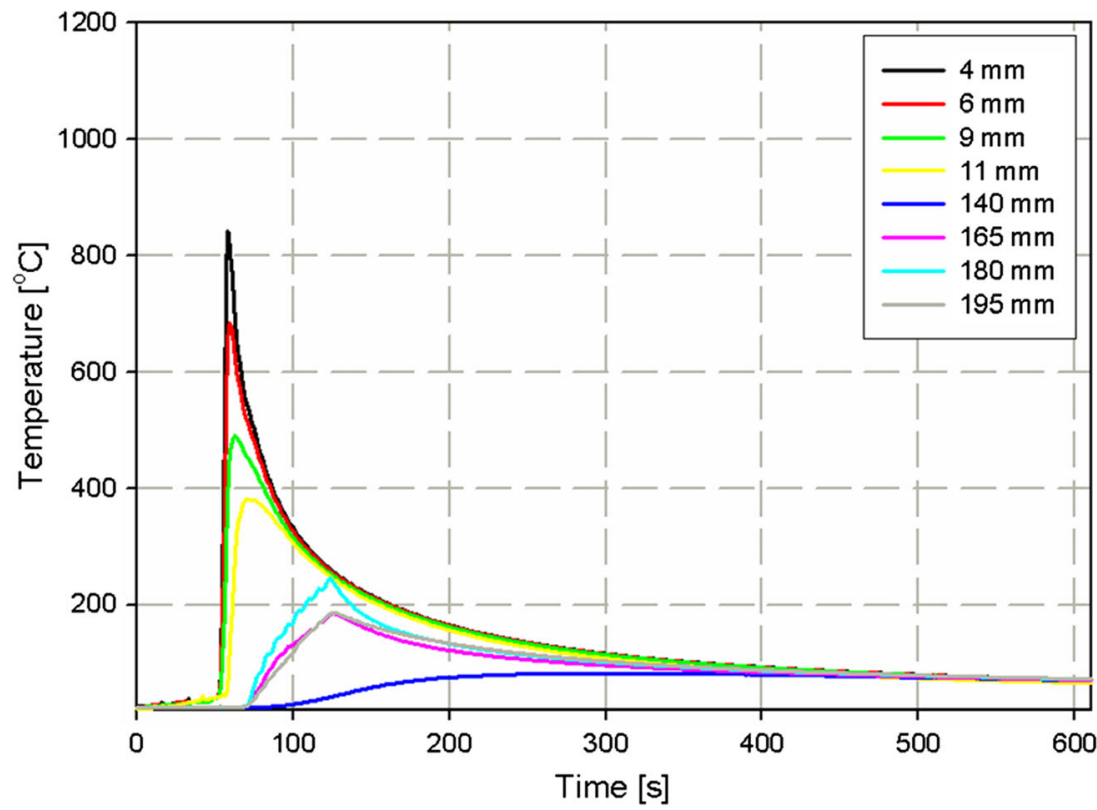


Fig. 13 Micrographs of the AH36 samples showing a close-up of the a the weld metal, $\mathbf{b}$ coarse-grained HAZ (of welding), c fine-grained HAZ (of welding) and $\mathbf{d}$ base metal, and e the top surface of the heated area beneath the burner after additional heating and $\mathbf{f}$ the underside surface of the heated area beneath the burner in additional heating
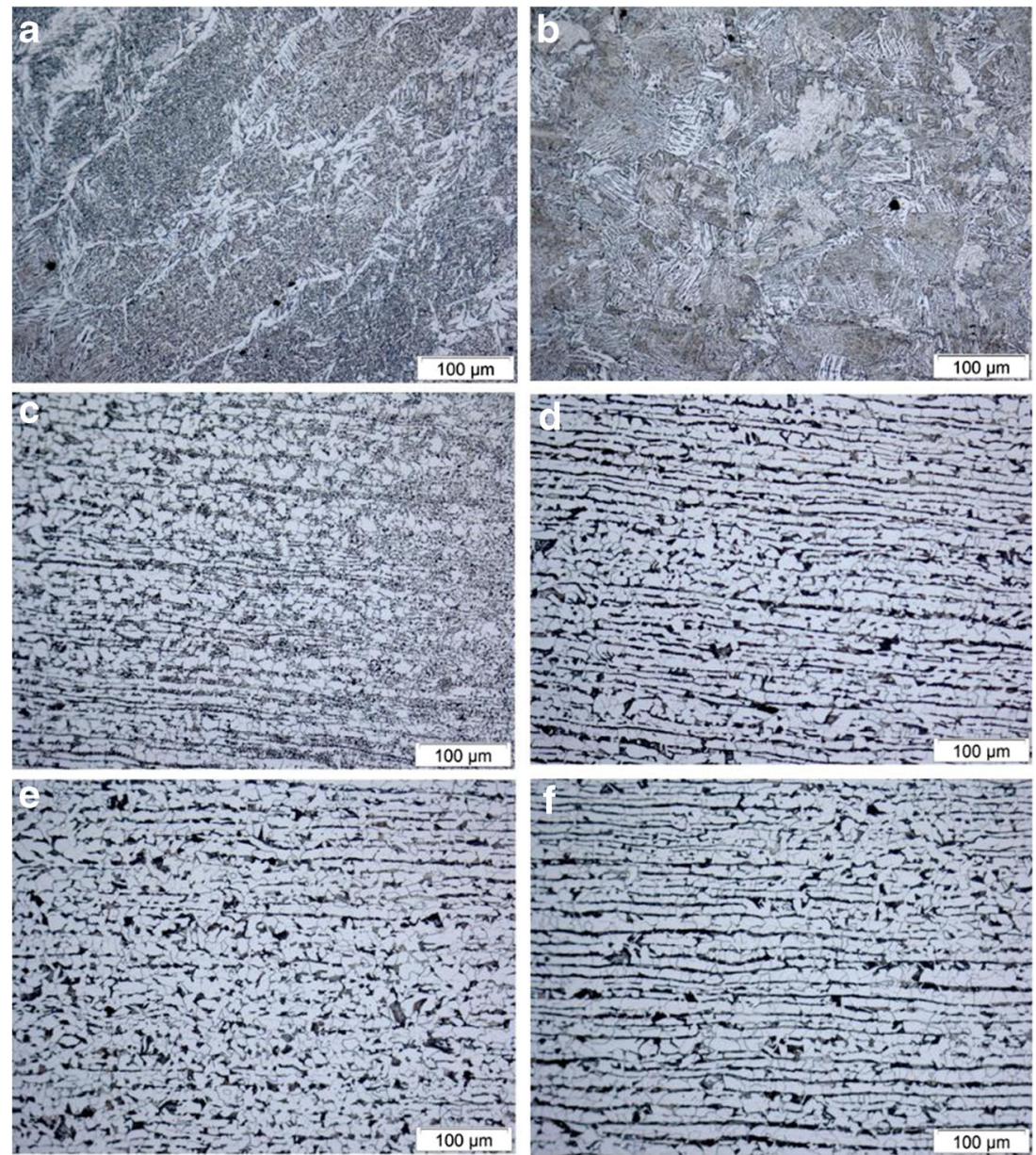

experiments. The effect of the burner separation on the distortion index is shown in Fig. 8. The distortion index decreases when the burners are located $193.5 \mathrm{~mm}$ to the weld centre line. The distance of the burners to the
Fig. 14 The cross section of the welds in conventional welding and welding with additional heating

\section{a}

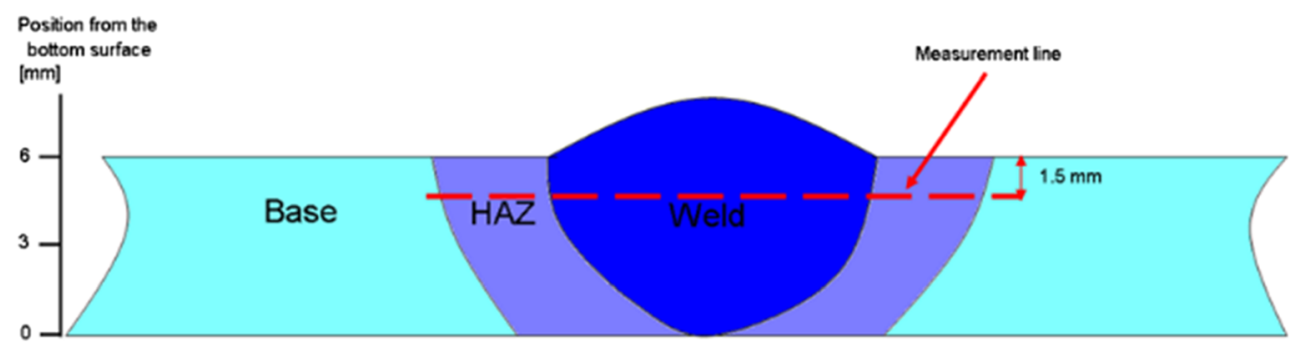

b

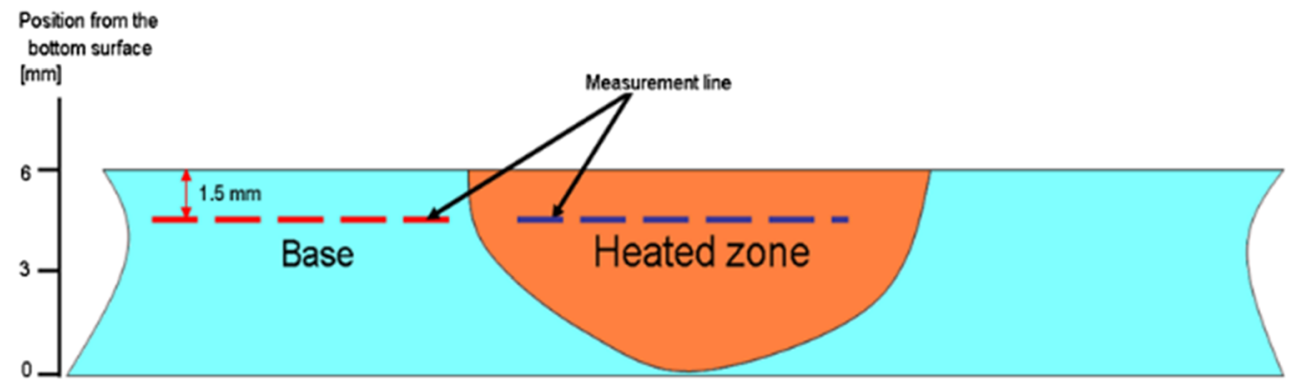


welding torch was varied. The results are shown in Fig. 9. The leading and the trailing positions of the burners both reduce the distortion index, but there is hardly any effect. The case in which the burners are located $180 \mathrm{~mm}$ trailing the welding torch is selected as the case with experimentally obtained minimum deformation. The out-of-plane deformation of the plate after conventional welding is compared to that of welding with additional heating for the selected case in Fig. 10. As can be seen, welding with additional heating reduces the plate deformation.

Figure 11 shows the temperature as a function of time at different positions from the weld centre line for conventional welding of AH36 samples, while the temperature profile during welding with additional heating of such samples is shown in Fig. 12.

Figure 13 shows the micrograph of the weld metal, coarsegrained HAZ (of welding), fine-grained HAZ (of welding), and the base metal of both conventionally welded material and welded material with additional heating. The heated areas beneath the burners in the case of welding with additional heating for both the top and underside surfaces of the sample are shown in the figure. Welding with additional heating has no influence on the microstructure of the weld metal and the HAZ (of welding). This is because of the similar thermal histories of the weld and HAZ (of welding) for both cases. It can be seen that the top surface of the heated area beneath the
Fig. 15 Hardness profiles for both a conventional welding and welding with additional heating and $\mathbf{b}$ the hardness profile in the side heated zones beneath the burners for $\mathrm{AH} 36$

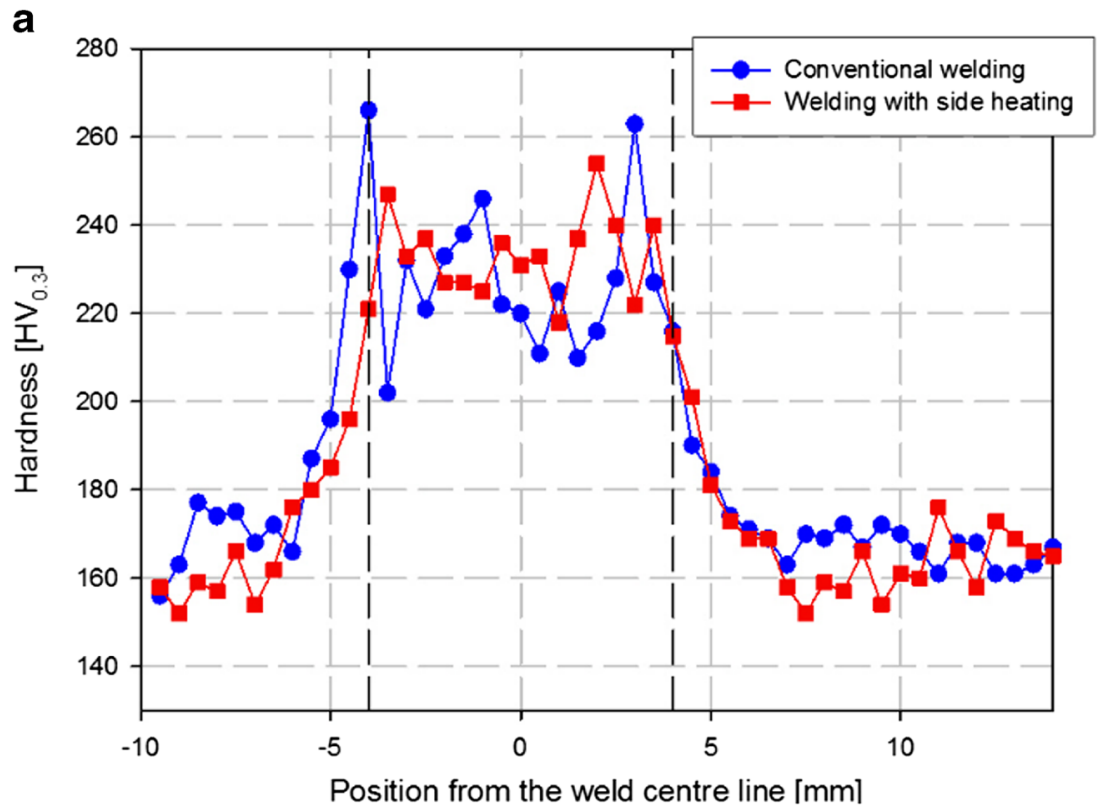

b

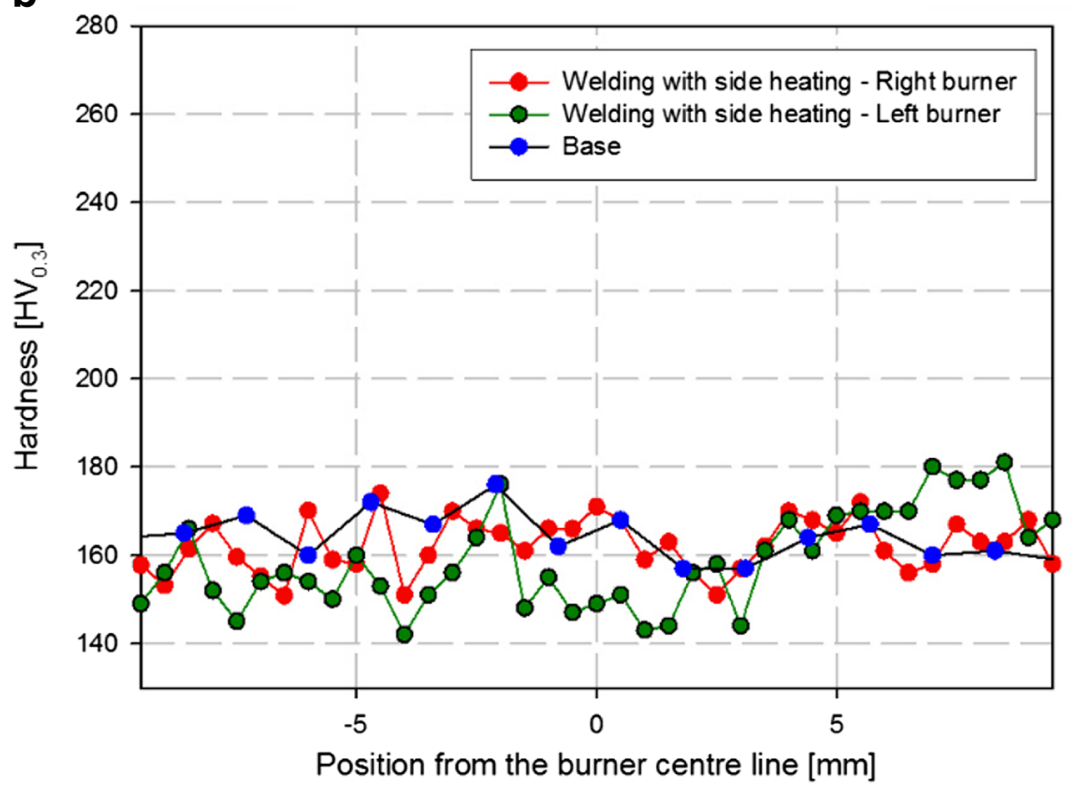


Fig. 16 Selected CCT diagram for transformation of austenite during cooling in AH36 steel [11]
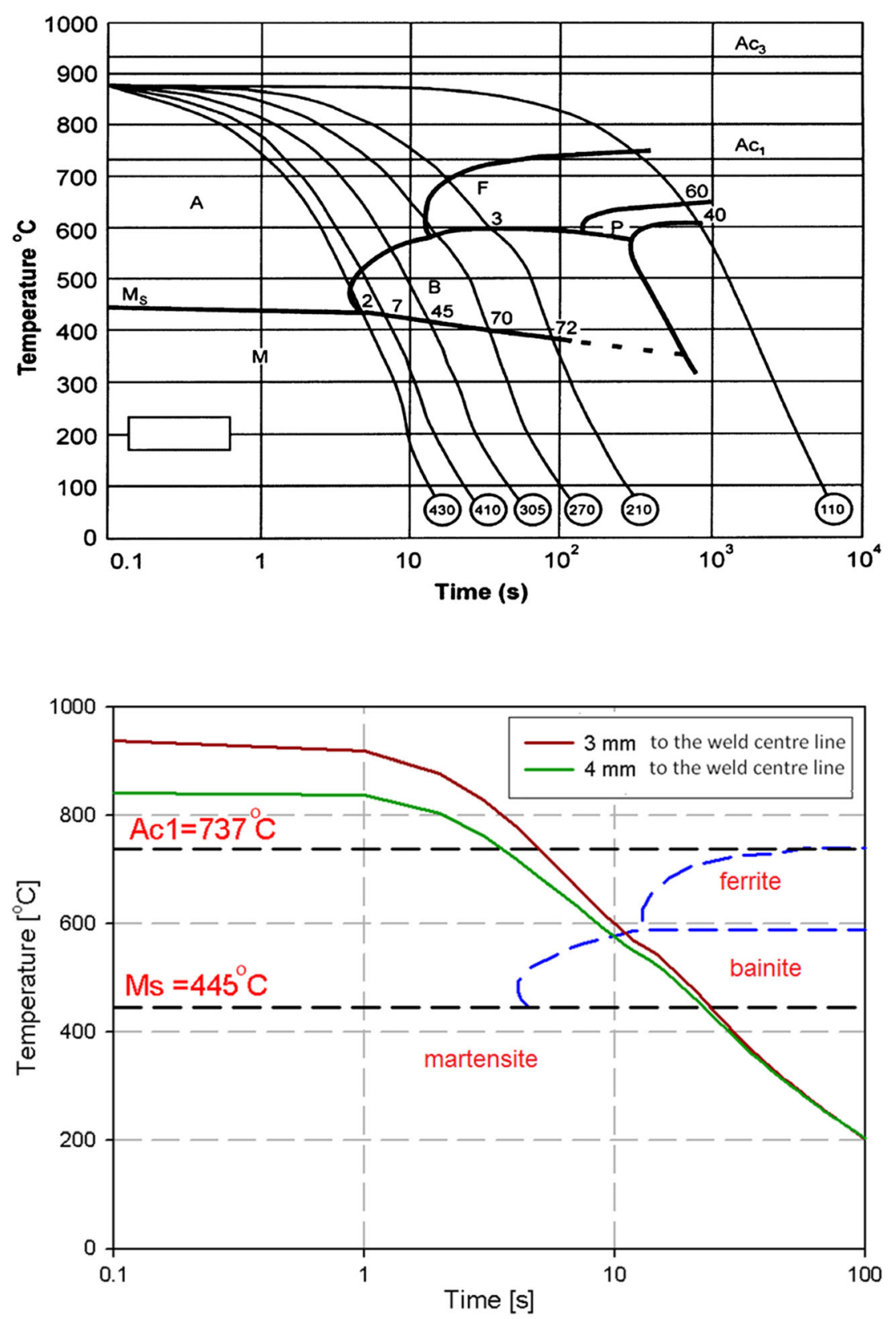

Fig. 17 The cooling cycle during conventional welding for two points located 3 and $4 \mathrm{~mm}$ from the weld centre line at the underside surface together with the parameterised CCT diagram burners has a tempered, while the underside surface has a microstructure close to the base metal.

Hardness profiles were measured at locations shown in Fig. 14. The hardness profile of the weld, HAZ (of welding) and the base metal for conventional welding and welding with additional heating is shown in Fig. 15a, while the hardness of the heated area beneath the burners is shown in Fig. 15b. The hardness of the heated area beneath the burners is slightly reduced. It is expected that such a reduction is due to tempering and reduction of internal energy.

The as-received condition of AH36 steel contains $15.5 \%$ pearlite and $84.5 \%$ ferrite. In large regions of the heat-affected zone, austenisation will occur, but not enough time is available for homogenisation. Figure 16 shows the CCT diagram used for austenite transformations in AH36 steel [11]. The temperature profiles, for two points located at underside surface of the plate, 3 and $4 \mathrm{~mm}$ from the weld centre line are shown together with the parameterised CCT diagram in

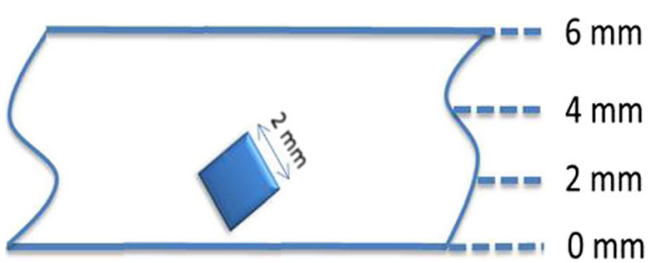

Fig. 18 The measurement position through thickness direction in AH36 plates 
Fig. 17. The temperature profiles are related to the points at the underside surface of the plate. As can be seen from the figure, at these two locations, the formation of hard constituents (like bainite) is expected.

The longitudinal residual stresses were measured perpendicular to the welding direction as a function of distance from the weld centre line. The origin is set at the plate centre. The rolling direction of the material is along the longitudinal direction. The position of the measurement in the through thickness direction is shown in Fig. 18. A gauge volume of $2 \times 2 \times 2 \mathrm{~mm}^{3}$ was used here.

The longitudinal residual stress distributions for conventionally welded plates and after welding with additional heating are shown in Fig. 19a, b, respectively. The longitudinal residual stresses are measured for the weld with additional heating with experimentally obtained minimum distortion. In both cases, the longitudinal residual stresses are measured after releasing the clamps. The releasing of the clamps takes place when the temperature of the plate had reached room temperature. It can be seen from the figure that the maximum tensile stresses of the welds in both conventional welding and welding with additional heating are at the same levels. However, the maximum compressive stresses in the case of welding with additional heating are slightly higher than those of conventional welding. By increasing the distance from the weld centre line to the plate edge, the compressive stresses in welding with additional heating decrease and change to tensile stresses.

The longitudinal residual stresses were also measured for both the conventional weld and the weld with additional
Fig. 19 Residual stress measurement results for $\mathrm{AH} 36$ after a conventional welding and b welding with additional heating
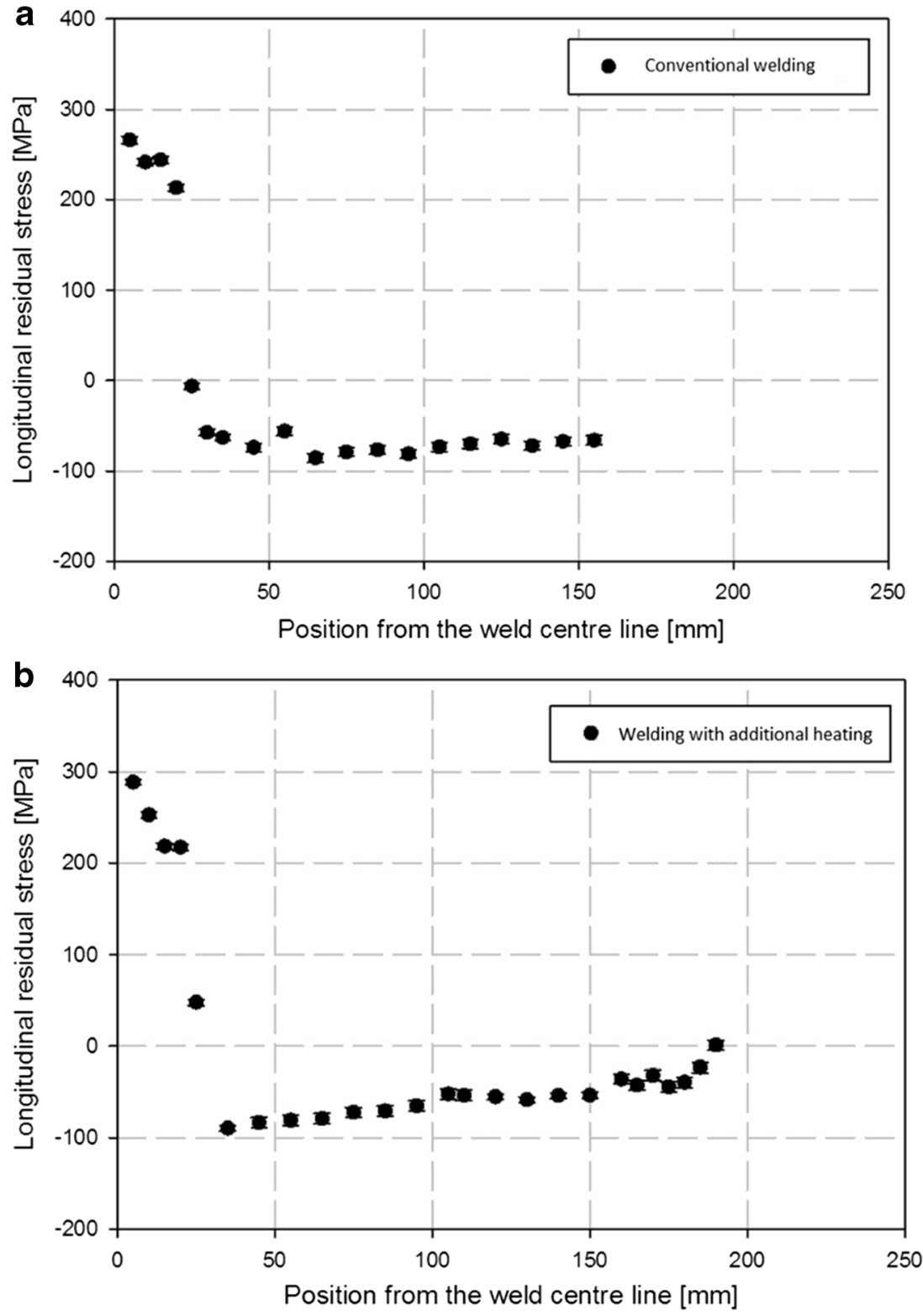
heating in the clamped conditions. In Fig. 20a, the result of the stress measurement for conventional welding for the plate in the clamped condition is shown and compared to the plate after releasing the clamps. It is seen that the absolute values of both tensile and compressive stresses are higher when the plate is in the clamped condition. The stress measurement for the plate before and after releasing the clamps in the case of the weld with additional heating is shown in Fig. 20b. The tensile stresses are higher in the clamped condition. However, the compressive stresses in the clamped condition are close to the un-clamped cases. In order to interpret the results, numerical models for both cases are used and discussed in the next section. Only from the experimental point of view, such deviations (between clamped and clamped release stress measurements) can be attributed to errors in the measurement. The results of the stress measurement for the clamped conditions were obtained from portable X-ray equipment (only at the plate surface). Therefore, different measurement methods are compared in the figure.

The main sources of errors in the measurements can be summarised as:

- For thick material, an error is introduced by the simplification of the 3D stress tensor to in-plane stress condition

- Human-related errors: sample positioning, alignment, reading and typing errors, etc.
Fig. 20 Residual stress measurement results for $\mathrm{AH} 36$ in the clamped condition for a a conventional weld and $\mathbf{b}$ a weld with additional heating
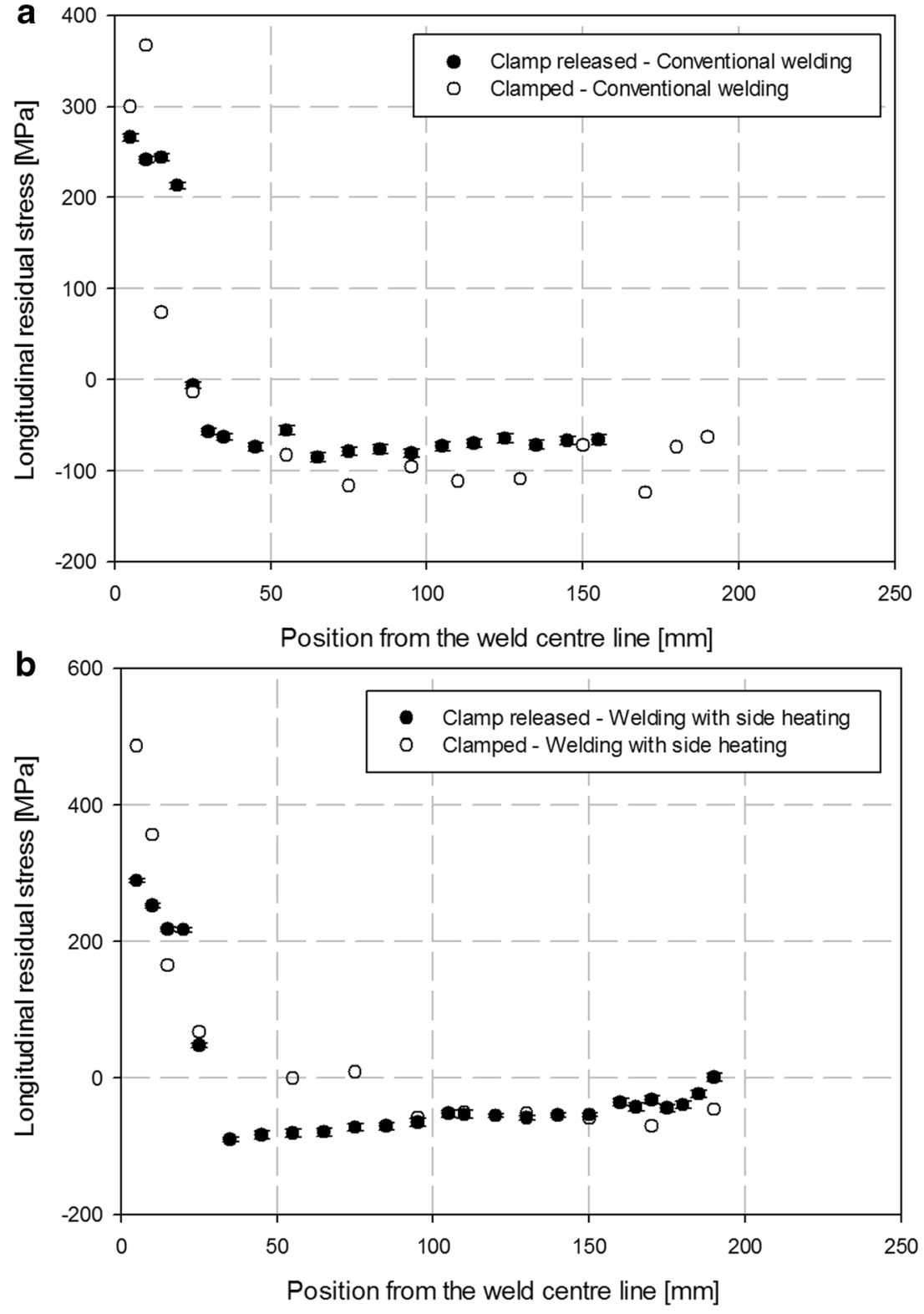
Fig. 21 Predicted temperature profiles for conventional welding of AH36 plates at the underside surface for different positions from the weld centre line
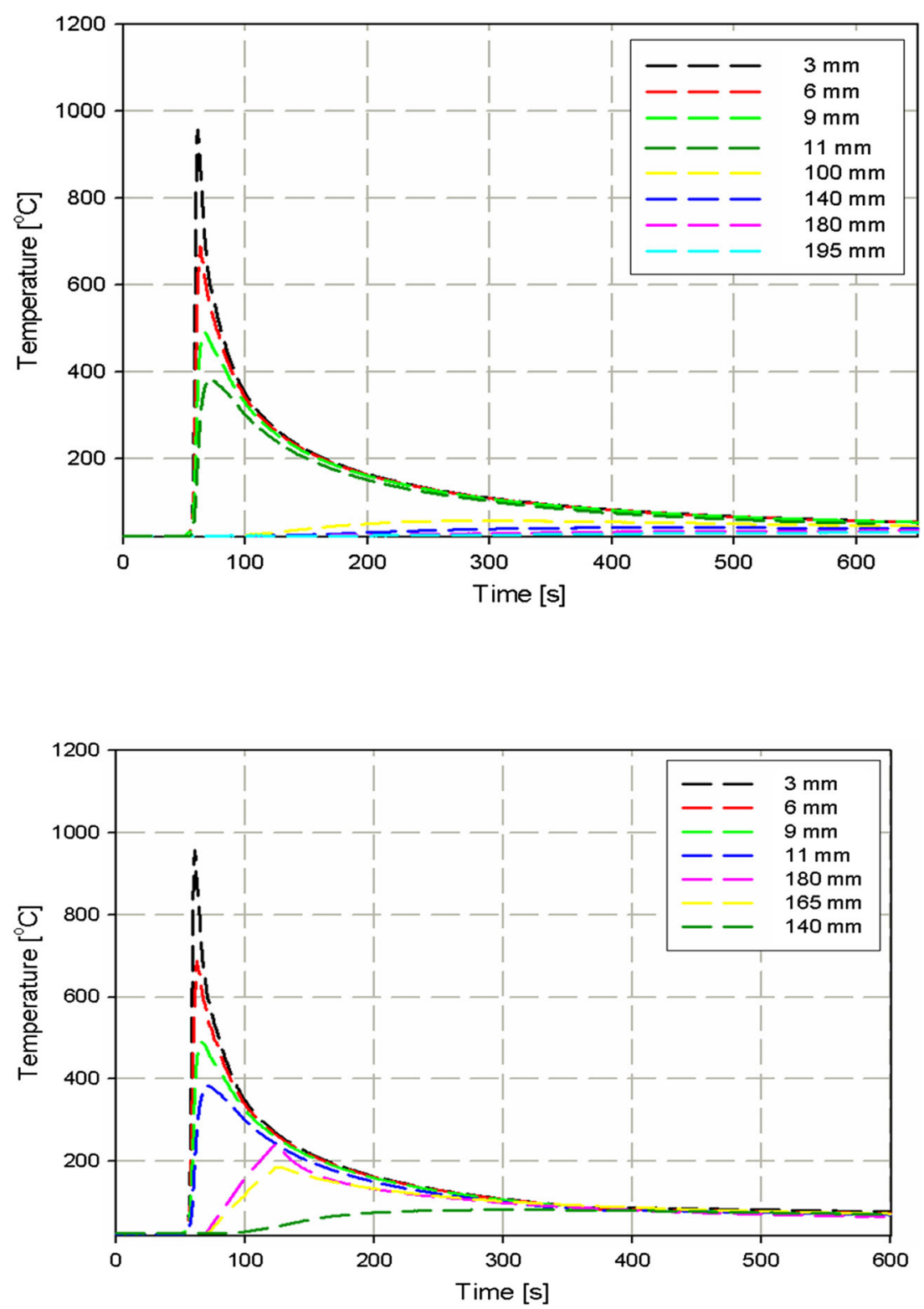

Fig. 22 Temperature prediction results for welding with additional heating of $\mathrm{AH} 3$ plates at different positions from the weld centre line. The temperature cycles are shown for the underside surface

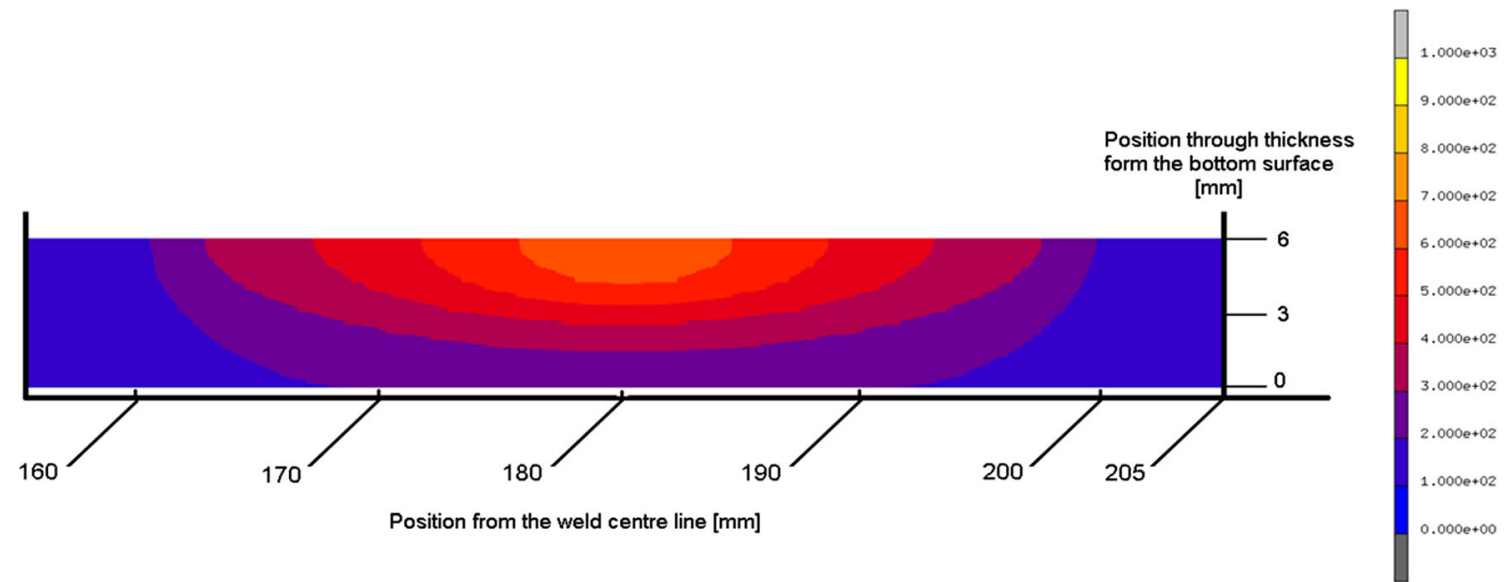

Fig. 23 Temperature distribution across the cross section of AH36 steel during welding with additional heating at the position of a burner. The burner is located $193.5 \mathrm{~mm}$ from the weld centre line. The temperature is in degrees Celsius 
- Sample positioning errors: definition of the origin, sample deformation, etc.

- Data analysis errors: peak fitting errors, elastic constants, stress-free lattice parameter, etc.

- Measurement errors: errors from neutron source, errors from measurement system (displacement), etc.

- Errors from sample: texture, grain size, shear stresses, outof-plane stresses, etc.

\section{Numerical predictions and discussions}

The heat input and heat loss model parameters have been set by comparing the results of the simulations with the experimental temperature measurements. Therefore, a trial and error method has been used to fit the numerical output to the experimental results by variations in the parameters. The predicted temperature profile during conventional welding of AH36 at
Fig. 24 The predicted final out-of-plane deformation of AH36 steel plate after a conventional welding and $\mathbf{b}$ welding with additional heating in the experimentally obtained minimum distortion. The scale is -8 to $+8 \mathrm{~mm}$ a

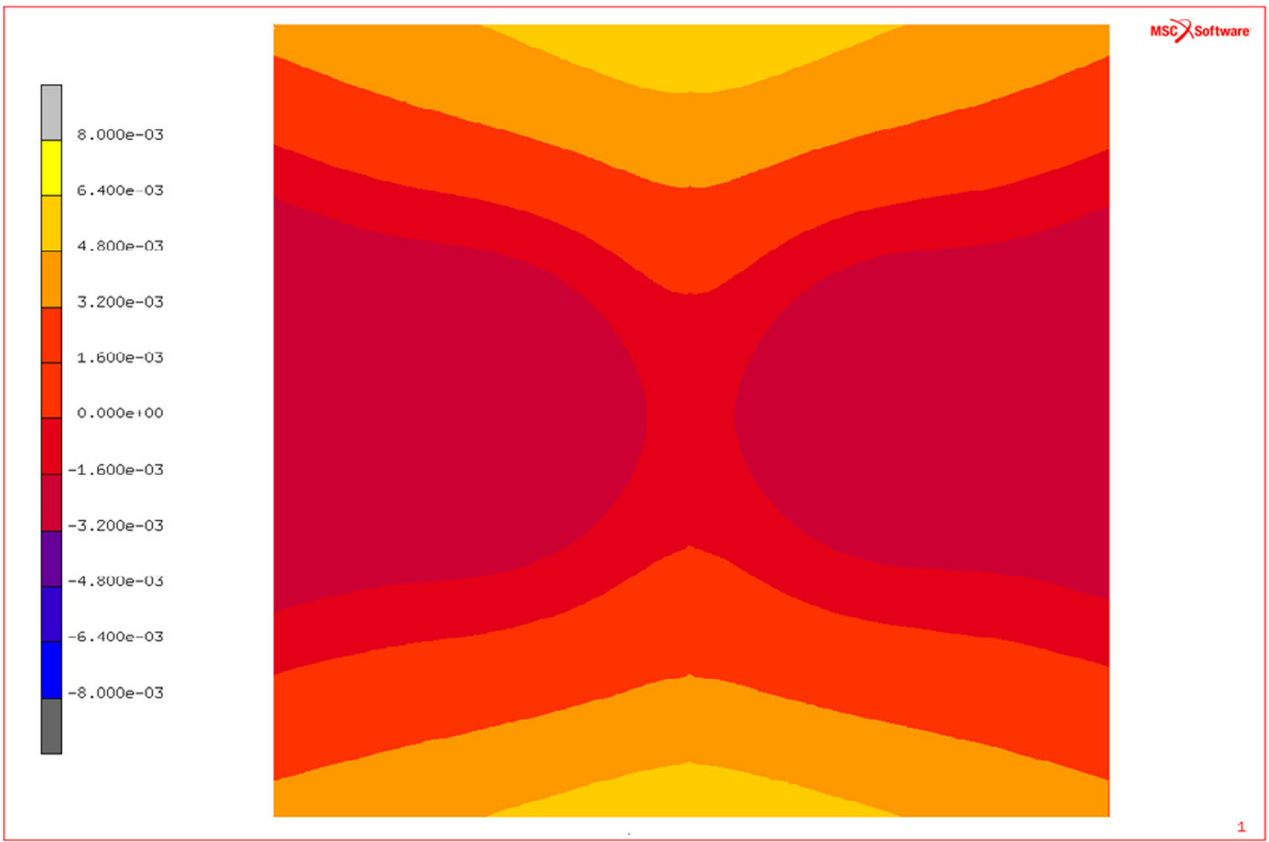

b

Welding with additional heating

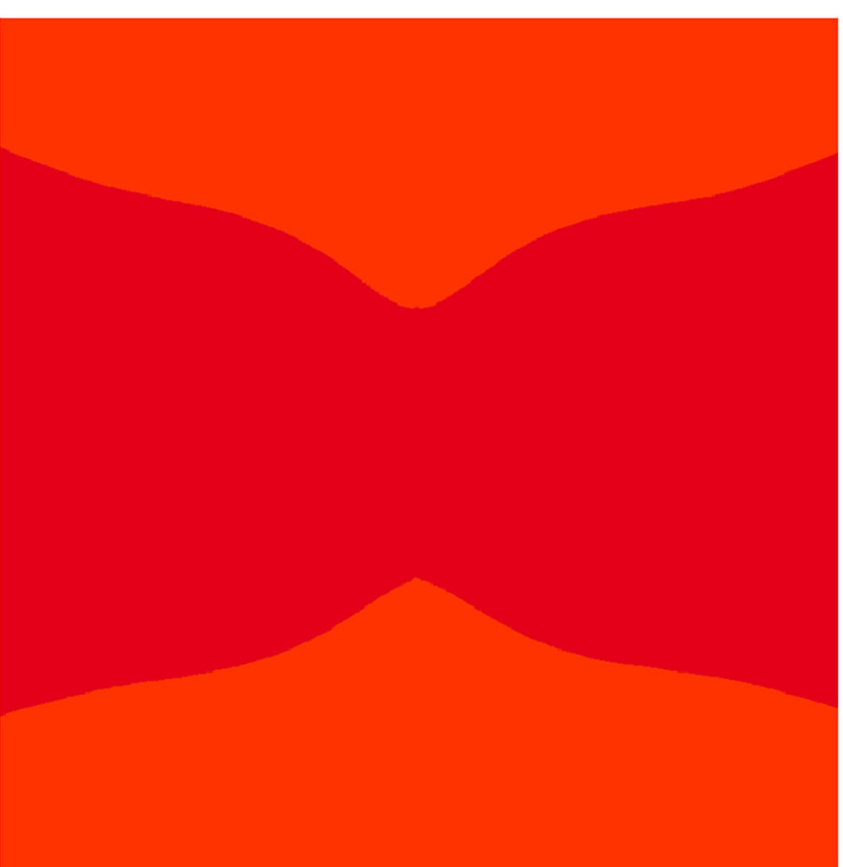


different positions from the weld centre line is shown in Fig. 21.

The prediction results of the temperature profile during welding with additional heating are shown in Fig. 22. The predictions are in a good agreement with the temperature measurements.

Figure 23 shows the prediction through thickness temperature distribution of AH36 plate beneath the burner during welding with additional heating. The burners are located $193.5 \mathrm{~mm}$ from the weld centre line. The maximum predicted temperature at the top surface of the plate beneath the burners when welding with additional heating for this material is $610^{\circ} \mathrm{C}$.

Figure 24 shows the numerical results for the out-of-plane deformation of AH36 steel after welding and welding with additional heating. The welding with additional heating was modelled using the experimentally obtained minimum distortion (trailing case). It is clear that the out-of-plane deformation of the plate is reduced using additional heating.

Figure 25 shows the predicted and the measured out-ofplane deformation for points located across the middle part of an AH36 plate from one edge to the other edge along a line perpendicular to the weld centre line for conventional welding and welding with additional heating. Comparing the numerical results and the measurements for conventional welding, it is seen that the predicted deformations are close to the experimental measurements for the points at the middle part of the plate. At the edges of the plates, there is a small deviation. Since the thermal field was predicted to be close to the
Fig. 25 Comparison between the predicted and measured out-of-plane deformation for points over the cross section across the middle of a AH36 plate for $\mathbf{a}$ a conventional weld and $\mathbf{b}$ a weld with additional heating
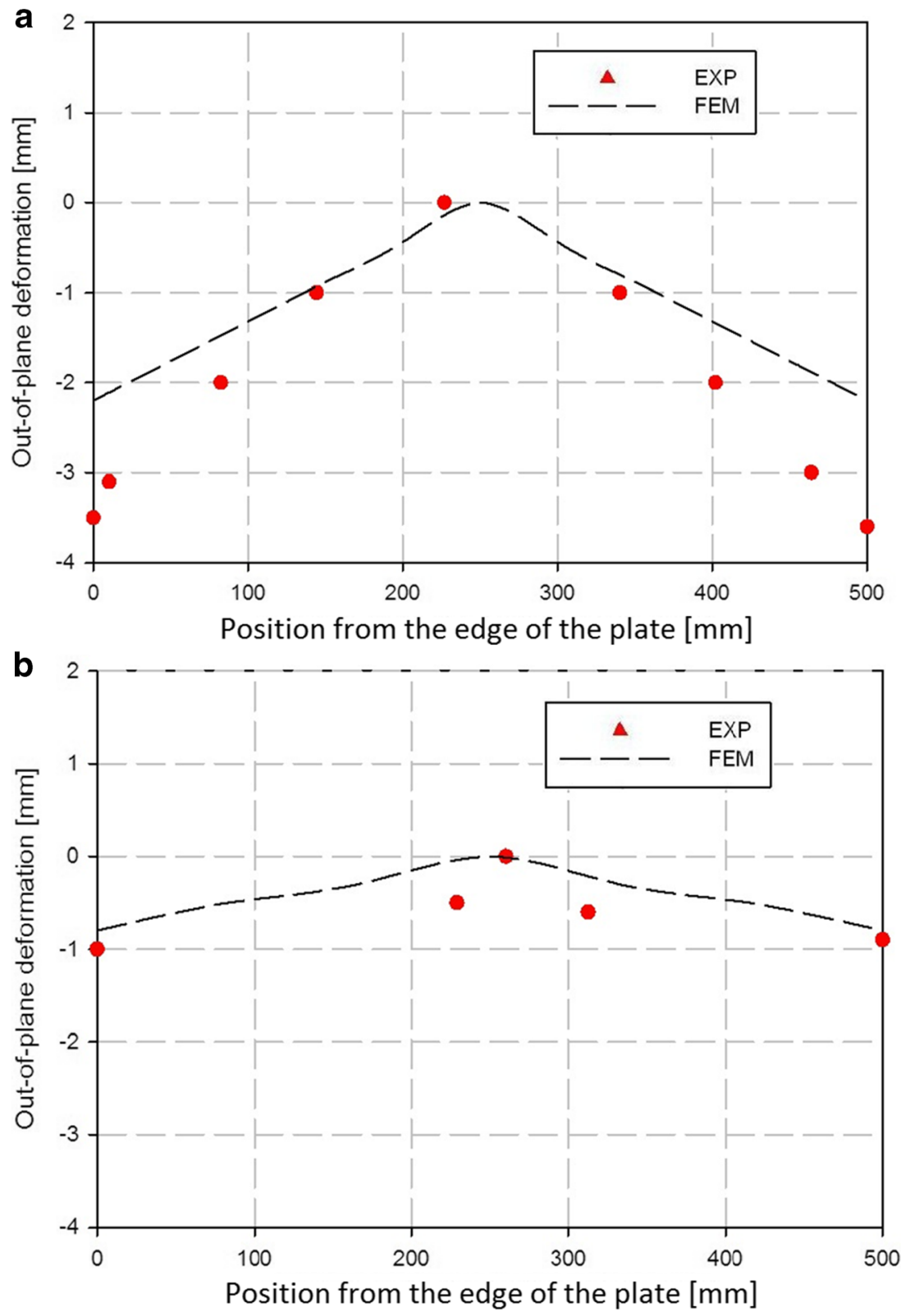
Table 5 The simulation results compared to the experimental results for AH36 plates, where the burners were positioned $193.5 \mathrm{~mm}$ from the weld centre line

\begin{tabular}{lll}
\hline \multirow{2}{*}{ Condition } & \multicolumn{2}{l}{ Distortion index $(\mathrm{mm})$} \\
\cline { 2 - 3 } & Numeric & Experiment \\
\hline Conventional welding & 8.8 & 5.5 \\
Welding with additional leading heating & 3.1 & 1.8 \\
Welding with parallel additional heating & 2.9 & No data \\
Welding with additional trailing heating & 2.6 & 1.5 \\
\hline
\end{tabular}

measured field, the main source of the deviation is related to the mechanical field. This includes the material properties and the clamping model explained before for the other two materials.
Table 5 shows the numerical results of the out-of-plane deformation of AH36 steel plate for different burner positions. It can be seen that the trailing situation provides the minimum distortion index both in the numerical and measurement results. The predictions are in agreement with the experiments.

Figure 26 shows a comparison between the prediction and the measured results of longitudinal residual stresses for AH36 plate. In Fig. 26a, the results of conventional welding are presented, while in Fig. 26b, the results of welding with additional heating are shown. In both cases, the clamps are released after welding. In the numerical results, it is predicted that after welding with additional heating, a tensile stress region is formed at the location of the burners (193.5 $\mathrm{mm}$ from the weld zone). This area has a very low stress level in conventional welding. It can
Fig. 26 Predicted longitudinal residual stresses after releasing the clamps for AH36 plates compared to the measurements for $\mathbf{a}$ conventional welding and $\mathbf{b}$ welding with additional heating
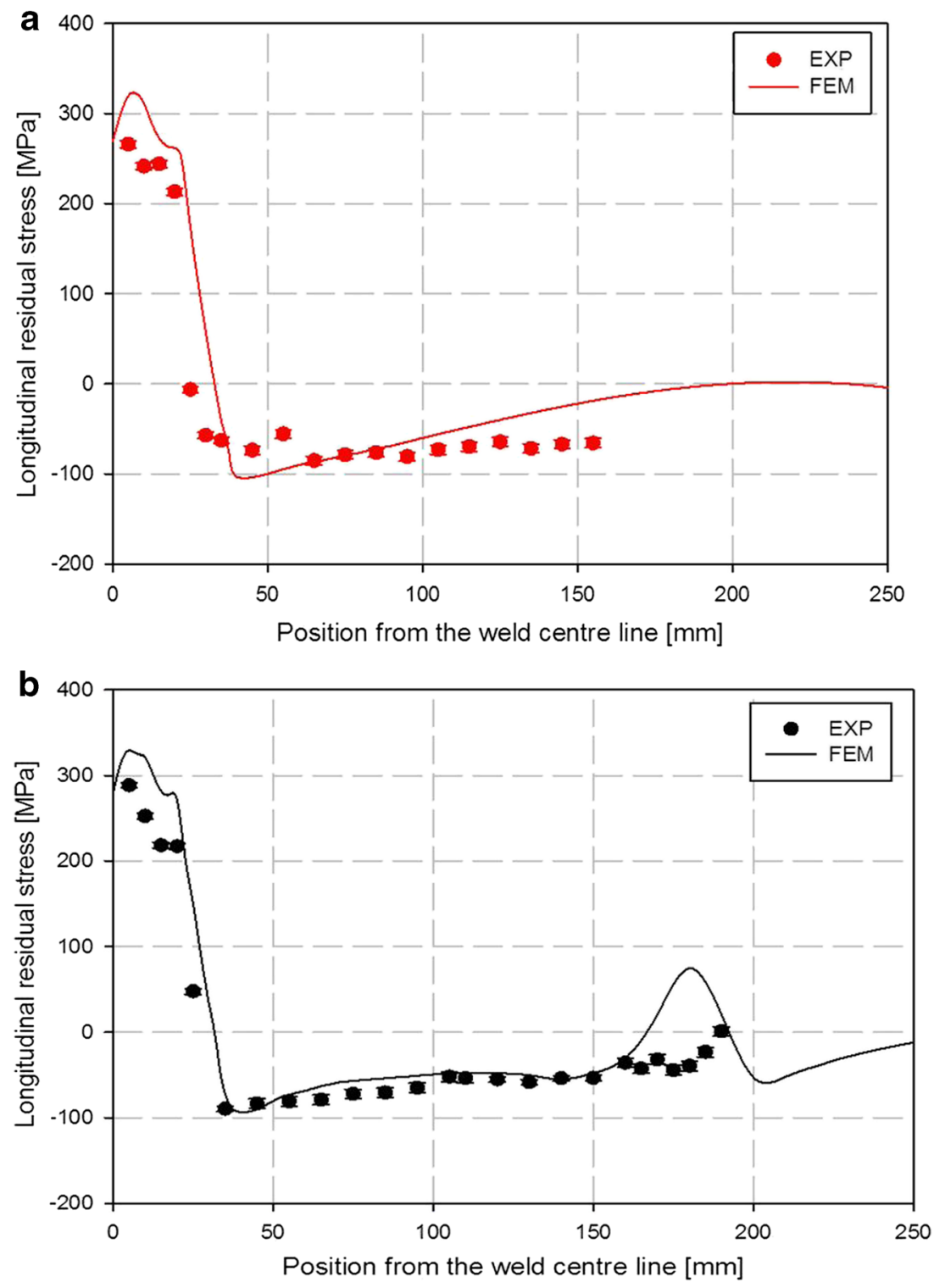
also be seen that the predictions indicate the same level of stresses in the weld and its HAZ in both conventional welding and welding with additional heating. However, the experimental results show a significant lower residual stress for the region beneath the burners in welding with additional heating. The main deviations between the numerical results and the experiments are attributed to the following:

- There is a possibility that the heat generated by the burners causes stress relieving. The temperature of the top surface beneath the burners is predicted to be around $600{ }^{\circ} \mathrm{C}$. The time of heating depends on the length of the burner $(240 \mathrm{~mm})$ and the heating speed $\left(4.5 \mathrm{~mm} \mathrm{~s}^{-1}\right)$. Both temperature and time needed for stresses relieving are available. Therefore, it is expected that two competing phenomena are occurring here: (1) stress build-up by the burners and (2) stress reduction by stress relieving. The winning term determines the final level of residual stresses. In the numerical model, phase transformations and microstructure changes have been excluded. In the predicted results, such tensile stress peaks at the position of the burners are expected. Implementation of these small changes in the numerical models is difficult. It should be noted here that the hardness measurement does not show significant change for the region beneath the burners. Full stress relieving needs more time than the heated time in the experiment. It is expected that stress relieving phenomenon occurs partially for this experimental heating time. Similar results have been observed in [14].
Fig. 27 Predicted longitudinal residual stresses before releasing the clamps for AH36 plates compared to the measurements for $\mathbf{a}$ conventional welding and $\mathbf{b}$ welding with additional heating
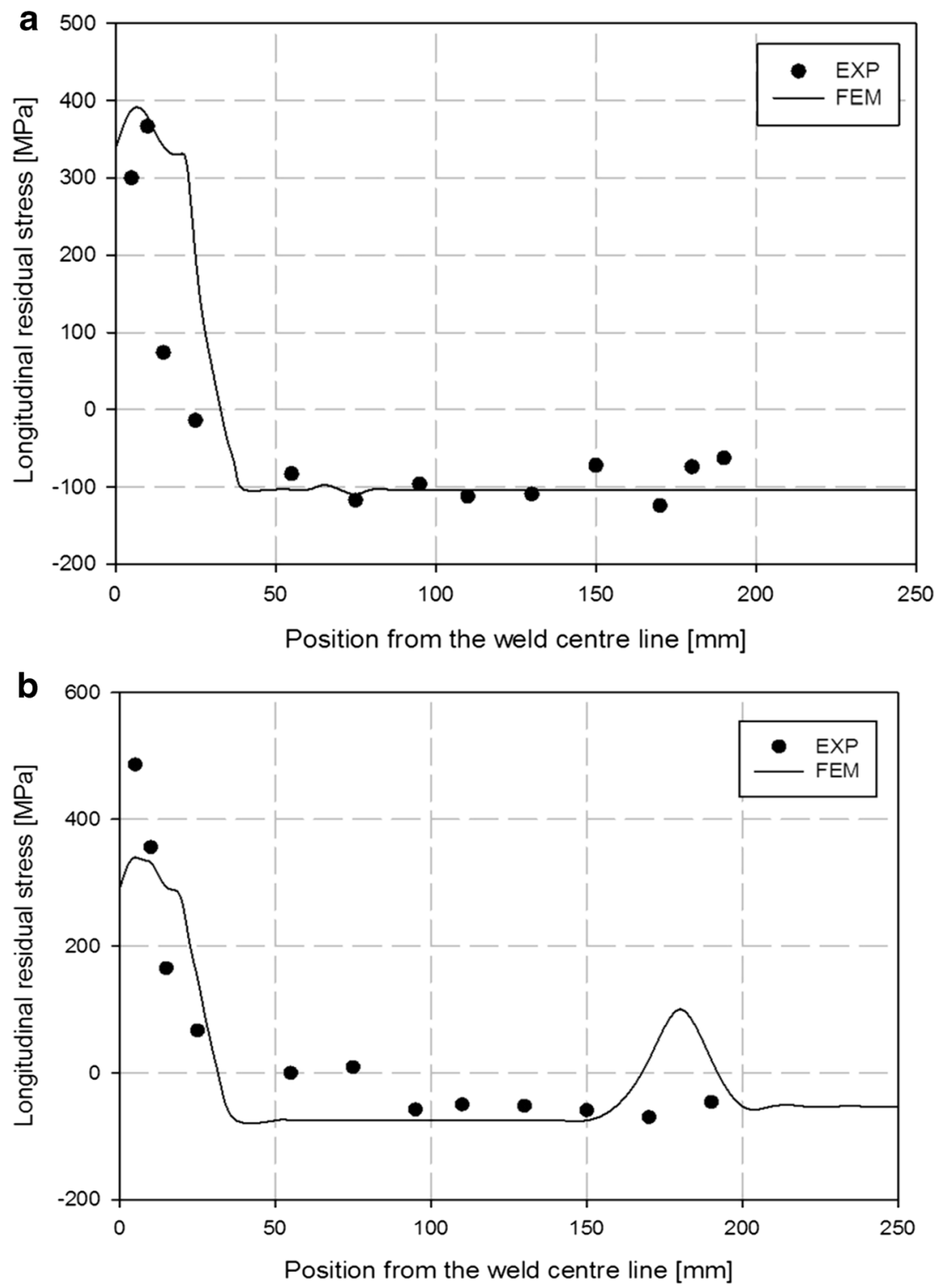
- The experimental source of errors explained in previous section should be taken into account in the interpretation.

- The numerical models exclude the phase transformations. However, the experimental results show lower stress in the region close to the weld in both conventional welding and welding with additional heating. Since the residual stresses are in a balanced condition, a change of these stresses somewhere in a plate causes a change somewhere else.

- All errors in material-related properties and the way of clamping in the numerical models explained for previous materials are valid here as well.

Figure 27 shows a comparison between the prediction and the measured results of longitudinal residual stresses for AH36 plate before releasing the clamps. In Fig. 27a, the results of conventional welding are presented, while in Fig. $27 \mathrm{~b}$, the results of welding with additional heating are shown. It is believed that the material properties contribute the most to the differences between the measured and the modelled residual stresses. Finally, it should be mentioned that the stresses have been measured only in the longitudinal direction. If more information for residual stresses in other directions were available for this thick material, it may be possible to determine more appropriate model parameters and obtain a better match between predictions and experiments.

\section{Conclusions}

The mechanisms of distortion reduction in welding with additional heating are complex. The complicated nature of welding stress and strain fields is increased by the large number of parameters involved in welding with additional heating. In welding with additional heating, it was found that the closer the burners were to the weld centre line, the higher deformation obtained. Moreover, the trend in distortion as a function of the burner positions (leading, parallel or trailing) relative to the welding torch was nonlinear. The results of distortion measurements indicated that the distortion of the plates is less sensitive to this parameter. The best temperature for welding with additional heating depends on many factors such as the position of the burners, the thermal and the mechanical material properties, the clamping system around the weld, the area heated by the burners, the geometry of the plate and the welding process. It was seen that the thermal field around the welds is not changed by additional heaters. The introduction of the additional heat by the burners is limited. Although at the top surface of the plate, higher temperatures are obtained. This causes minor changes in microstructure and mechanical properties. For AH36 steel plate, the top surface of the heated areas beneath the burners showed a tempered microstructure, while the microstructure of the underside surface is not affected. In the region beneath and close to the burners, compressive residual stresses are reduced in welding with side heating compared with those of conventional welding of AH36. Finite element models were constructed to simulate and investigate the thermal and the mechanical fields in both conventional welding and welding with additional heating. The assumptions made in the high temperature material properties, plastic strain resetting, modelling of clamps and the additional heaters resulted in some discrepancies between the models and the measurements. For the conventional welding process, close matches between the temperature, residual stress and distortion measurements and the numerical predictions were observed. The main sources of deviation in the thermal modelling of both conventional welding and welding with side heating are related to the thermal material data at elevated temperature. The essential feature of the welding with side heating is the creation of a temperature peak at the location of the burners. The temperature distribution in the weld zone and the HAZ (of welding) remains unchanged. The predicted residual stresses are close to the measured values for both conventionally welded plates and plates after side heating. The characteristic of side heating from a numerical point of view is the creation of tensile residual stresses at the location of the burners (tensile peaks were observed in the numerical results for the regions beneath the burners).

Acknowledgments This research was carried out under project number MC8.06252 in the framework of the Research Program of the Materials innovation institute M2i (www.m2i.nl), the former Netherlands Institute for Metals Research.

Open Access This article is distributed under the terms of the Creative Commons Attribution 4.0 International License (http:// creativecommons.org/licenses/by/4.0/), which permits unrestricted use, distribution, and reproduction in any medium, provided you give appropriate credit to the original author(s) and the source, provide a link to the Creative Commons license, and indicate if changes were made.

\section{References}

1. Preston RV (2000) Modelling of residual stresses in welded aerospace alloys. $\mathrm{PhD}$ thesis, University of Cambridge

2. Masubuchi K (1980) Analysis of welded structures. Pergamon Press, USA

3. Pilipenko A (2001) Computer simulation of residual stress and distortion of thick plates in multi-electrode submerged arc welding, $\mathrm{PhD}$ thesis. Norwegian University of Science and Technology (NTNU), Trondheim

4. van der Aa EM (2007) Local cooling during welding: prediction and control of residual stresses and buckling distortion. $\mathrm{PhD}$ thesis, Delft University of Technology. 
5. Takeno S Method for preventing welding distortion of sheet metals, Japanese Patent JP 4052079.

6. ASTM A 131/A 131 M-08: Standard Specification for Structural Steel for Ships, ASTM International (http://www.astm.org/ Standards/A131.htm).

7. AWS A5.18 (2001) Specification for Carbon Steel Electrodes and Rods for Gas Shielded Arc Welding, AWS.

8. DIN EN ISO 5172 (2006) Gas welding equipment, Blowpipes for gas welding, heating and cutting-Specifications and tests.

9. Goldak J (1984) A finite element model for welding heat sources. Metallurgical Transactions 15B:299-305

10. Pilipenko A (2001) Computer simulation of residual stress and distortion of thick plates in multi-electrode submerged arc welding-Their mitigation techniques, PhD Thesis. NTNU, Trondheim
11. Tsirkas SA, Papanikos P, Kermanidis T (2003) Numerical simulation of the laser welding process in the butt joint specimens. Journal of Material Processing and Technology 134:59-69

12. Schenk T (2011) Modeling Welding Distortion: the influence of clamping and sequencing and sensitivity analysis. $\mathrm{PhD}$ thesis, $\mathrm{TU}$ Delft.

13. MSC, Marc User Manual, Version 2007R1, MSC. Software corporation, 2007

14. IIman MN, Ismail R, Iswahyudi S, Muslih MR (2011) An experimental study of movingly localized heating based stress relieving for control of residual stress and its beneficial effect on fatigue crack growth rate of steel welded structure. Proceedings of 64th annual assembly and international conference of International Institute of Welding, Chennai, pp $583-591$ 